\title{
COMMENTARY
}

\section{Adipose tissue alterations in critical illness: a paradox as to patient outcomes}

\author{
Charles E Wade
}

See related research by Marques et al., http://ccforum.com/content/17/5/R193

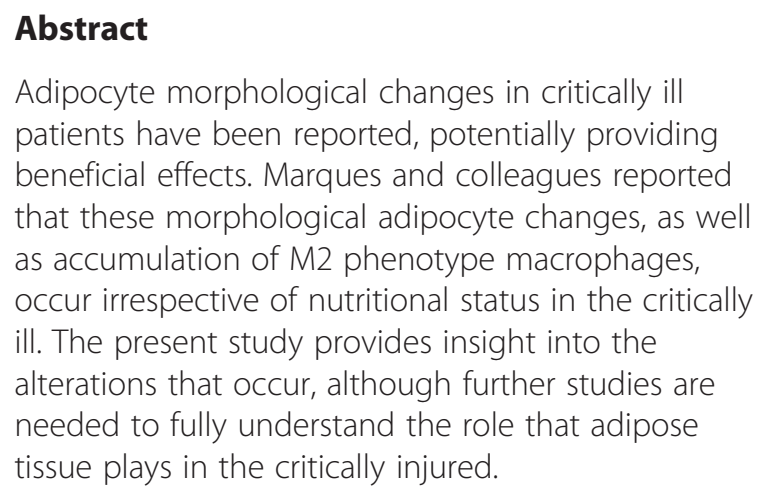

As the incidence of obesity increases, its impact on the care and outcomes of the critically ill patient has become an issue. There are numerous concerns when caring for obese patients, which include the impact on survival to the ability of the care provider to move the patient. In terms of survival of these patients, both positive and negative outcomes have been associated with obesity, specifically body mass index, which has been termed the 'obesity paradox' [1,2]. This inconsistency in survival has stimulated an increased interest in the role of adipose tissues in critical illness.

Adipose tissue has generally been viewed as an inert tissue that was a store for excess energy. In the past two decades, adipose tissue has become recognized as a dynamic tissue involved in the regulation of metabolism, the inflammatory response, coagulation and insulin sensitivity, all of which are major elements in the response to critical illness. Langouche and colleagues [1-3] have demonstrated that adipocytes undergo morphological changes in patients with critical illness, resulting in smaller adipocytes with increased glucose and lipid storage capabilities and increased accumulation of M2

Correspondence: Charles.E.Wade@uth.tmc.edu

Center for Translational Injury Research, University of Texas Health Science Center at Houston, 6431 Fannin St MSB 5.204, Houston, TX 77030, USA phenotype macrophages. These changes are suggested to impart beneficial effects improving patient outcomes.

In their present study, Marques and colleagues [1] postulated that these changes were independent of the nutritional status of the subject. They employed the long-term cecal ligation and puncture (CLP) mouse model of sepsis and made two comparisons. The first is the comparison of healthy animals to animals with CLP who were fed approximately $66 \%$ of their daily requirement. The CLP animals demonstrated a significant reduction in total body fat, smaller adipocytes and increased deposition of M2 macrophages, changes similar to those they observed in patients. In critically ill patients, the percentages of daily caloric and protein requirements met are in the order of 60 to $65 \%$, the same as the mice in the present study [4]. This leaves open the question of whether the changes in adipose tissue morphology are a function of critical illness or a result of malnutrition.

Their second comparison was between the CLP mice that were fed $66 \%$ of the dietary requirement and a severely restricted group that received about $15 \%$. There were minimal differences between the groups. In the absence of a difference, they conclude that the observed changes are not a function of nutrition. However, severe malnutrition may result in a decrease in metabolism, attenuating the taxing of metabolic stores. In rodents, this is associated with torpor. A similar reduction in energy expenditure is noted in severely malnourished patients in an attempt to balance energy intake and expenditure $[5,6]$. In the present study, energy expenditures, especially the magnitude of hypermetabolism due to infection, were not measured; thus, the full impact of nutritional intake cannot be adequately assessed.

The authors do provide additional data from critically ill patients reaffirming their earlier observations, and assess the effects of restricted nutritional intake. These data allow the animal data to be put into context. In the patients, the nutritional differences were the result of 
providing parenteral supplementation. In the patients who had increased supplementation, there appears to still be an energy deficit, especially in light of a $70 \%$ infection rate. The question that has not been addressed in the present effort is: if adequate nutrition to meet energy requirements, including the initial deficit, is provided, would the changes in adipose tissue be observed? This would fully address the hypothesis that nutritionindependent factors evoke the morphological changes in adipose tissue during critical illness.

The authors have previously posed the question of whether these changes in adipose tissue during critical illness are adaptive or protective [7]. The present work scratches the surface with regard to alterations of adipose tissue in critical illness, but leaves open the role of adipose tissue in outcomes of patients with critical illness.

\section{Abbreviations}

CLP: Cecal ligation and puncture.

\section{Competing interests}

The author declares that he has no conflicts of interests.

Published: 20 Sep 2013

\section{References}

1. Marques MB, Perre SV, Aertgeerts A, Derde S, Guiza F, Casaer MP, Hermans $G$, Van den Berghe G, Langouche L: Critical illness induces nutrientindependent adipogenesis and accumulation of alternatively activated tissue macrophages. Crit Care 2013, in press.

2. Marques MB, Langouche L: Endocrine, metabolic, and morphologic alterations of adipose tissue during critical illness. Crit Care Med 2013, 41:317-325.

3. Langouche L, Marques MB, Ingels C, Gunst J, Derde S, Vander Perre S, D'Hoore A, Van den Berghe G: Critical illness induces alternative activation of M2 macrophages in adipose tissue. Crit Care 2011, 15:R245.

4. Alberda C, Gramlich L, Jones N, Jeejeebhoy K, Day AG, Dhaliwal R, Heyland DK: The relationship between nutritional intake and clinical outcomes in critically ill patients: results of an international multicenter observational study. Intensive Care Med 2009, 35:1728-1737.

5. Jan BV, Lowery SF: Systemic response to injury and metabolic support. In Schwartz's Principles of Surgery. 9th edition. Edited by Brunicardi FC, Andersen DK, Billiar TR, Dunn DL, Hunter JG, Matthews JB, Pollock RE. New York: McGraw-Hill Companies Inc; 2010:16-49.

6. Long C: Energy expenditure of major burns. J Trauma 1979, 19:904-906.

7. Langouche L, Perre SV, Thiessen S, Gunst J, Hermans G, D'Hoore A, Kola B, Korbonits M, Van den Berghe G: Alterations in adipose tissue during critical illness: an adaptive and protective response? Am J Respir Crit Care Med 2010, 182:507-516.

$10.1186 / \mathrm{cc} 13013$

Cite this article as: Wade: Adipose tissue alterations in critical illness: a paradox as to patient outcomes. Critical Care 2013, 17:188 